\title{
Specific Features of Structural-Phase State and Properties of Reactor Pressure Vessel Steel at Elevated Irradiation Temperature
}

\author{
E. A. Kuleshova, ${ }^{1,2}$ B. A. Gurovich, ${ }^{1}$ E. V. Krikun, ${ }^{1}$ A. S. Frolov, ${ }^{1}$ D. A. Maltsev, ${ }^{1}$ \\ Z. V. Bukina, ${ }^{1}$ M. A. Saltykov, ${ }^{1}$ and A. G. Balikoev ${ }^{3}$ \\ ${ }^{1}$ National Research Center "Kurchatov Institute", Kurchatov Sq. 1, Moscow 123182, Russia \\ ${ }^{2}$ National Research Nuclear University "MEPhI" (Moscow Engineering Physics Institute), Kashirskoe Highway 31, \\ Moscow 115409, Russia \\ ${ }^{3}$ State Research Center of the Russian Federation JSC RPA “CNIITMASH", Sharikopodshipnikovskaya St. 4, Moscow 115088, Russia
}

Correspondence should be addressed to B. A. Gurovich; gurovich_ba@nrcki.ru

Received 1 February 2017; Revised 1 March 2017; Accepted 16 March 2017; Published 3 April 2017

Academic Editor: Keith E. Holbert

Copyright (C) 2017 E. A. Kuleshova et al. This is an open access article distributed under the Creative Commons Attribution License, which permits unrestricted use, distribution, and reproduction in any medium, provided the original work is properly cited.

\begin{abstract}
This paper considers influence of elevated irradiation temperature on structure and properties of 15Kh2NMFAA reactor pressure vessel (RPV) steel. The steel is investigated after accelerated irradiation at $300^{\circ} \mathrm{C}$ (operating temperature of VVER-1000-type RPV) and $400^{\circ} \mathrm{C}$ supposed to be the operating temperature of advanced RPVs. Irradiation at $300^{\circ} \mathrm{C}$ leads to formation of radiationinduced precipitates and radiation defects-dislocation loops, while no carbide phase transformation is observed. Irradiation at a higher temperature $\left(400^{\circ} \mathrm{C}\right)$ neither causes formation of radiation-induced precipitates nor provides formation of dislocation loops, but it does increase the number density of the main initial hardening phase-of the carbonitrides. Increase of phosphorus concentration in grain boundaries is more pronounced for irradiation at $400^{\circ} \mathrm{C}$ as compared to irradiation at $300^{\circ} \mathrm{C}$ due to influence of thermally enhanced diffusion at a higher temperature. The structural-phase changes determine the changes of mechanical properties: at both irradiation temperatures irradiation embrittlement is mainly due to the hardening mechanism with some contribution of the nonhardening one for irradiation at $400^{\circ} \mathrm{C}$. Lack of formation of radiation-induced precipitates at $T=400^{\circ} \mathrm{C}$ provides a small $\Delta T_{K}$ shift $\left(17^{\circ} \mathrm{C}\right)$. The obtained results demonstrate that the investigated $15 \mathrm{Kh} 2 \mathrm{NMFAA}$ steel may be a promising material for advanced reactors with an elevated operating temperature.
\end{abstract}

\section{Introduction}

To optimize electricity generation new designs of nuclear power plants are being developed and the existing ones are being modified. One of the concepts of VVER-type reactor modification is the development of a supercritical watercooled reactor. Many years of experience in thermal power engineering have shown that the use of supercritical water significantly increases the plant efficiency and optimizes the pumps operation, since water has no phase transitions at supercritical parameters.

To assess the possibility of using the existing 15Kh2NMFAA steel as a material of VVER-type reactor pressure vessel (RPV) with supercritical parameters radiation and thermal stability of the steel was studied under irradiation at $400^{\circ} \mathrm{C}$ in comparison with the corresponding parameters of the steel after irradiation at $300^{\circ} \mathrm{C}$.

Radiation and thermal stability of VVER-type RPV materials imply, first of all, resistance to embrittlement while maintaining the strength properties, since these parameters determine the safety of reactor in extreme operation modes in the event of an emergency reactor cooling with cold water. Numerous studies [1-4] have shown the embrittlement of low-alloy steels to be due to two possible embrittlement mechanisms, the relative contribution of which can change during operation. The first mechanism is the hardening one $[5,6]$, associated with the change of yield strength of the material due to formation of new or changing contribution of the 
TABLE 1: The chemical composition of 15Kh2NMFAA steel.

\begin{tabular}{ccccccccccc}
\hline & \multicolumn{1}{c}{ Composition, wt.\% } & & & $\mathrm{S}$ & $\mathrm{P}$ & $\mathrm{Cu}$ \\
\hline 15Kh2NMFAA & 0.16 & 0.45 & 0.29 & 1.18 & 2.08 & 0.62 & 0.10 & $<0.004$ & $<0.005$ & $<0.04$ \\
\hline
\end{tabular}

TABLE 2: The studied states of the material.

\begin{tabular}{|c|c|c|c|c|}
\hline Material & State & Irradiation temperature & Fluence, $10^{22} \mathrm{~m}^{-2}$ & Flux, $10^{16} \mathrm{~m}^{-2} \mathrm{~s}^{-1}$ \\
\hline 15Kh2NMFAA & As-received & - & - & - \\
\hline 15Kh2NMFAA & Intermediate temperature irradiation & $300^{\circ} \mathrm{C}$ & 45.3 & 6.64 \\
\hline 15Kh2NMFAA & Intermediate temperature irradiation & $400^{\circ} \mathrm{C}$ & 44.0 & 6.16 \\
\hline 15Kh2NMFAA & Segregation provoking treatment & - & - & - \\
\hline
\end{tabular}

initial pinning points of dislocation. These pinning points are as follows: radiation defects, radiation-induced phases, and minor second-phase inclusions. The second embrittlement mechanism is the nonhardening one $[7,8]$ associated with a reduction of intergranular cohesion due to grain boundary segregation of impurity and alloying elements.

Irradiation of reactor pressure vessel (RPV) steels at temperatures of $300-500^{\circ} \mathrm{C}$ refers to the intermediate temperature irradiation, characterized by the presence of both interstitial atoms and vacancies causing sufficient diffusion mobility of impurity and alloying atoms. This in principle should contribute to the formation of both radiation-induced phases and grain boundary segregation.

\section{Materials and Research Methods}

The paper considers the influence of the irradiation temperature increase on the structural-phase state and properties of 15Kh2NMFAA RPV steel.

Table 1 shows the chemical composition of the studied material.

The material was investigated in different states: asreceived, after accelerated irradiation in a research reactor in different irradiation modes, and after special segregation provoking treatment. Table 2 shows the states of the material studied in this paper.

The specimens were irradiated in a research reactor with fast neutrons flux, exceeding the one typical for operating conditions of VVER-1000 reactors. The irradiation embrittlement rate is known to decrease in VVER-1000 RPV steels with high $(>1.35 \%)$ bulk nickel content under irradiation with high flux $[1,11-13]$.

The flux effect becomes significant if flux increases by more than an order of magnitude which requires the flux effect corrections when using research results of materials after accelerated irradiation. In the studied 15Kh2NMFAA steel specimens the bulk nickel content is $1.18 \mathrm{wt} . \%$, assuming no flux effect and allowing the use of accelerated irradiation to assess the radiation stability of the steel specimens under operating conditions of the RPV.

A special step heat treatment provoking segregation (segregation provoking treatment) was carried out to reveal susceptibility of the material to thermal embrittlement. The time of thermal exposure at each step was chosen so that at

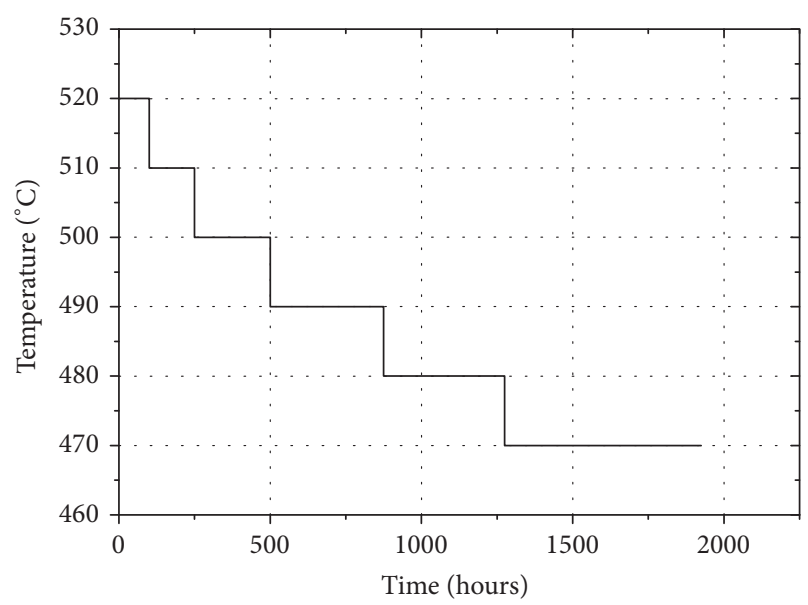

FIGURE 1: The mode of segregation provoking treatment [9].

each temperature phosphorus diffusion length was the same. After long-term temperature exposure at $T=470^{\circ} \mathrm{C}$ the steel was cooled at a rate of $2^{\circ} \mathrm{C} / \mathrm{min}$ down to a temperature of $T=$ $300^{\circ} \mathrm{C}$ and then cooled by turning off the furnace.

The mode of segregation provoking treatment is shown in Figure 1.

In order to reveal the features and mechanisms of radiation embrittlement of RPV steel at elevated irradiation temperature $\left(400^{\circ} \mathrm{C}\right)$, as compared to operating temperature of VVER-1000-type RPV $\left(300^{\circ} \mathrm{C}\right)$, and to assess thermal stability of the steel we used the following research methods. Mechanical tests (impact and static tension tests) were performed to evaluate degradation of mechanical properties of the steel and to assess hardening of the steel (the change of the yield strength values), correspondingly, after segregation provoking treatment and irradiation. Scanning (SEM) and transmission electron microscopy (TEM) were performed to assess changes in the structural-phase state and determine the contribution of radiation-induced structural elements in steel irradiation embrittlement (the hardening mechanism). Atom probe tomography (APT) was carried out to assess the contribution of radiation-induced structural elements in the radiation embrittlement of steel, as well as changes in the composition of the phases. Fractographic studies were performed to determine the maximum portion of brittle 
intergranular fracture $(\eta)$ in the fracture surfaces of Charpy specimens after impact tests, which correlates with the level of phosphorus concentration in grain boundaries of the material. Auger electron spectroscopy (AES) was performed to assess segregation processes (nonhardening mechanism of radiation embrittlement) and determine the concentration of phosphorus in grain boundaries of the material.

2.1. Mechanical Tests. Material properties degradation under operation was evaluated by the results of impact and static tension tests.

The critical brittleness temperature $\left(T_{K}\right)$ was determined based on the results of impact tests of Charpy V-notched specimens. Impact tests were conducted in a hot cell using the RKP-300 impact pendulum machine with potential energy of $300 \mathrm{~J} . T_{K}$ values were revealed from the impact test results in accordance with [14]. The mechanical properties change of VVER-1000 RPV steels, which is due to the influence of operational factors (high operating temperatures and irradiation), was defined as the difference between the corresponding values for the specimens after segregation provoking treatment or irradiation and as-received specimens.

Yield strength values were determined based on the results of uniaxial static tension tests of specimens with the working part diameter of $3 \mathrm{~mm}$ performed on the Instron1253 universal testing machine. The results were processed in accordance with Russian standard [15].

2.2. Electron Microscopy Studies. TEM investigations were performed using a Titan-300 (FEI) transmission electron microscope in accordance with [16]. Research specimens were prepared from RPV steel blanks by bilateral electrochemical thinning using the Struers TenuPol-5 machine.

To visualize the small structural elements (with sizes less than $\sim 1.3 \mathrm{~nm}$ ), such as second phases in the matrix and dislocation loops, the weak beam method was used which allows obtaining the contrast only from the area of locally distorted matrix [17].

2.3. Atom Probe Tomography Studies. The number density and composition of radiation-induced precipitates were determined by means of atom probe tomography using Cameca LEAP-4000 HR atom probe in voltage pulse mode. The specimens were prepared by focused ion beam method using FEI Helios NanoLab 600 DualBeam microscope from the studied TEM specimens. The results were processed using Cameca IVAS 3.6.12 software by maximum separation method (MSM). The MSM parameters were chosen individually for each of the studied datasets from the comparison of the real and randomized datasets using IVAS cluster size distribution and cluster count distribution functions. Precipitates composition was assessed by the cluster concentration profile.

2.4. Fractographic Studies. Fractographic studies were conducted to determine the maximum portion of brittle intergranular fracture $(\eta)$ in the fracture surfaces of specimens after impact tests. For each half of tested V-notched Charpy specimen the portions of the fracture modes in the fracture surface were determined (in the first place-the portion of brittle intergranular fracture).

Glagolev's method [18] was used to estimate the portions of areas with different fracture modes (ductile transcrystalline fracture, cleavage, quasi-cleavage, brittle intercrystalline fracture, and ductile intercrystalline fracture) in the total fracture surface after Charpy tests at different temperature. The method is to count the number of points of a uniform grid, accounting for each structural component in the test image.

For this purpose at least 50 fields of view are randomly selected in scanning electron microscope at magnifications $\times 1000-3000$. In each of the fields of view the prevailing (about $85 \%$ ) fracture mode is determined (one of the listed above or combined modes).

The share of each fracture mode is estimated according to the following formula [18]:

$$
f_{i}=\frac{\sum i+\sum_{k}((i+k) / 2)}{N},
$$

where $i$ counts the areas with the estimated fracture mode; $k$ counts the areas with the rest fracture modes; $N$ is the total number of fields of view.

At that the relative error of determining the portion of brittle intergranular fracture in the fracture surface of specimens does not exceed $10-15 \%$ [18].

Fractographic studies were carried out on V-notched Charpy specimens $\left(10 \times 10 \mathrm{~mm}^{2}\right.$ cross-section $)$ in as-received state, after segregation provoking treatment, and after irradiation at different temperature. Immediately before studying the specimens were placed for 5 minutes in an ultrasonic bath with ethanol to purify the fracture surface from mechanical contamination.

The studies were performed on Zeiss Supra 40 VP scanning electron microscope. The fracture surface analysis of the specimens was carried out at accelerating voltage of $20 \mathrm{kV}$ : at low magnification (50-100) to obtain an overview of the destruction process and at magnifications $\times 100-1500$ for the detailed analysis of the fracture relief at the microlevel.

For each state of material several specimens after impact tests were studied. Earlier studies [10, 19] have shown that there is a temperature dependence of the portion of brittle intergranular fracture. This fracture mode appears just above the lower-shelf temperature, increases as the temperature approaches the region of ductile-to-brittle transition, reaching a maximum value typical for the steel in the analyzed state, and then drops to zero as the test temperature reaches the upper shelf region (see Figure 2).

Thus, fractographic studies were conducted on several specimens after impact tests in the temperature range of ductile-to-brittle transition and then on the basis of all the data the maximum portion of brittle intergranular fracture was determined for the analyzed state.

Since the portion of brittle intergranular fracture in fracture surfaces of Charpy specimens correlates with the phosphorus GB concentration, measuring $\eta$ values allows making a rapid assessment of the segregation processes 


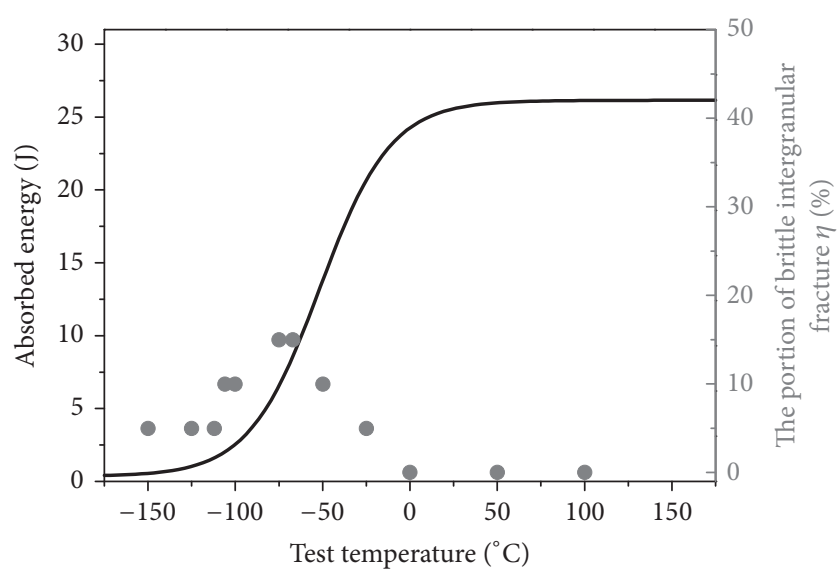

FIGURE 2: Typical dependence of portion of brittle intergranular fracture and absorbed energy on impact test temperature [10].

degree in steels in various states and judging the nonhardening mechanism contribution to materials embrittlement [10].

2.5. Auger Electron Spectroscopy Studies. Phosphorus concentration in grain boundaries was measured using the PHI700 scanning Auger Nanoprobe on the circular notched cylindrical specimens ( $3.2 \mathrm{~mm}$ diameter and $18 \mathrm{~mm}$ height). The specimens were cooled by the liquid nitrogen and fractured in a special attachment inside the ultrahigh vacuum (UHV) chamber at a pressure of $\leq 7 \cdot 10^{-10}$ torr. To perform accurate measurements regions of brittle fracture along grain boundaries free of cleavages or nonmetallic inclusions were selected in a scanning electron microscope mode. As the lateral resolution of the Auger Nanoprobe goes down to $\mathrm{nm}$ range [20] even tiny areas of brittle fracture along grain boundaries could be detected and measured (e.g., in the as-received specimens where Glagolev's method did not reveal any significant portion of brittle intergranular fracture mode-see Figure 6(a)).

GB phosphorus content was evaluated as fraction of phosphorus monolayer coverage according to [21]

$$
C_{P}=K_{P M} \frac{I_{P}}{I_{M}},
$$

where $I_{P}$ and $I_{M}$ are the phosphorus $(P)$ and metal $(M)$ peak intensities at the differentiated Auger spectra. The matrix coefficient for $P$ element adsorbed on the matrix boundary is determined from the following formula:

$$
K_{P M}=2\left[\frac{\lambda_{P}\left(E_{P}\right) \cos \theta}{a_{P}}\right]\left[\frac{1+r_{P}\left(E_{P}\right)}{1+r_{M}\left(E_{P}\right)}\right] \frac{I_{M}^{\infty}}{I_{P}^{\infty}},
$$

where $\lambda_{P}\left(E_{P}\right)$ is the mean-free path of an Auger electron of energy $E_{P}$ in the matrix; $a_{P}, r_{P}$, and $r_{M}$ are terms describing the backscattering, $\theta$ is emission angle with respect to the specimen surface normal, and $I_{P}^{\infty}$ and $I_{M}^{\infty}$ are pure elements signal intensities specified in [20].

The GB elemental AES analysis is described in more detail in [22].
For each state 5-8 specimens were examined with the total number of various GBs measurements on the brittle intergranular fracture surface of 50-100. The results of AES studies are presented as frequency histograms of phosphorus concentration in monolayer fractions (Figures 5, 9, and 12) and as the change of average concentration of phosphorus as compared to the as-received state (Table 5). The histogram width always significantly exceeds the error of AES concentration measurements. The scatter of data in the histogram is mainly caused by the presence of the grain boundaries with different phosphorus content in the fracture surface due to different mutual orientation of the grains and therefore different ability for impurity accumulation [21, 23-25].

\section{Results and Discussion}

3.1. Study of Thermal Stability of the Steel. SEM and TEM studies of the phase composition of as-received specimens of $15 \mathrm{Kh} 2 \mathrm{NMFAA}$ steel have shown that the tempered bainite matrix contains initial hardening phases: $\mathrm{Me}_{7} \mathrm{C}_{3}$, (Mo, $\mathrm{Cr})_{2}$ C-type carbides, $\mathrm{V}(\mathrm{C}, \mathrm{N})$ carbonitrides, and nonmetallic inclusions (manganese sulfides $\mathrm{MnS}$ and silicon oxides $\mathrm{SiO}_{2}$ ). Table 5 shows the results of study of the hardening phases in as-received specimens and after segregation provoking treatment (to be found in the Discussions).

Table 5 demonstrates that segregation provoking treatment does not change the phase composition of the steel: number density and sizes of carbides and carbonitrides remain practically unvaried. Lack of phase composition changes causes no change in strength characteristics: yield strength and tensile strength of the studied steel after segregation provoking treatment remain the same. This means that the initial hardening phases do not contribute to the change of strength properties during thermal exposure.

To assess the contribution of grain boundary segregation to the shift of critical brittleness temperature $\left(\Delta T_{K}\right)$ fractographic studies of the specimens after segregation provoking treatment were conducted.

It should be noted that segregation provoking treatment was carried out in such a way that the studied steel was exposed to the temperature within the range of maximum temper embrittlement during practically achievable time for maximum grain boundary segregation.

Results of fractographic analysis for as-received specimens of $15 \mathrm{Kh} 2 \mathrm{NMFAA}$ steel and the specimens after segregation provoking treatment are shown in Table 3. Figure 3 shows the corresponding ductile-to-brittle transition curves.

Figure 4 shows APT mapping for as-received specimen and the one after segregation provoking treatment, indicating no formation of hardening precipitates. A grain boundary enriched by $\mathrm{Ni}, \mathrm{Mn}, \mathrm{P}, \mathrm{Si}$, and $\mathrm{C}$ can be easily seen in the image of the specimen after segregation provoking treatment (Figure 4(b)).

Table 3 shows that the share of brittle intergranular fracture increases significantly due to the segregation provoking treatment (up to $30 \%$ ), indicating formation of grain boundary segregation of impurities (phosphorus). With no contribution of the hardening mechanism this causes the observed shift of the critical brittleness temperature $\left(35^{\circ} \mathrm{C}\right)$. 
TABLE 3: Results of fractographic analysis for 15Kh2NMFAA steel specimens in different states.

\begin{tabular}{|c|c|c|c|c|c|c|c|c|c|}
\hline \multirow[b]{2}{*}{ State, $T_{K}$} & \multirow[b]{2}{*}{$\begin{array}{l}\text { Specimen } \\
\text { number }\end{array}$} & \multicolumn{8}{|c|}{ Portion of different fracture modes (\%) } \\
\hline & & $T_{\text {test }},{ }^{\circ} \mathrm{C}$ & $\begin{array}{c}\text { Absorbed } \\
\text { energy, J }\end{array}$ & Ductile & $\begin{array}{l}\text { Quasi- } \\
\text { cleavage }\end{array}$ & Cleavage & $\begin{array}{c}\text { Brittle inter- } \\
\text { granular } \\
\text { fracture }\end{array}$ & Grain size* $^{*}$ & $\eta, \%$ \\
\hline \multirow{6}{*}{ As-received } & 3115 & -100 & 18 & - & 80 & 20 & - & 50 & \multirow{6}{*}{0} \\
\hline & 31110 & -87 & 37 & 5 & 75 & 20 & - & 100 & \\
\hline & 31111 & -81 & 12 & - & 80 & 20 & Traces & 50 & \\
\hline & 31112 & -78 & 127 & 40 & 55 & 5 & Traces & 50 & \\
\hline & 3114 & -75 & 169 & 40 & 50 & 10 & - & 50 & \\
\hline & 3113 & -50 & 201 & 65 & 30 & 5 & - & 100 & \\
\hline \multirow{7}{*}{$\begin{array}{l}\text { Segregation } \\
\text { provoking } \\
\text { treatment }\end{array}$} & $315-12$ & -90 & 22 & - & 70 & 15 & 15 & 100 & \multirow{7}{*}{30} \\
\hline & $315-11$ & -70 & 55 & 15 & 55 & 10 & 20 & 100 & \\
\hline & $315-3$ & -50 & 9.9 & 5 & 55 & 10 & 30 & 50-100 & \\
\hline & $315-8$ & -44 & 9.5 & 10 & 60 & 15 & 15 & $50-100$ & \\
\hline & $315-10$ & -40 & 169 & 30 & 40 & Traces & 30 & 100 & \\
\hline & $315-7$ & -37 & 118 & 25 & 45 & 10 & 20 & 100 & \\
\hline & $315-2$ & -25 & 186 & 40 & 40 & 5 & 15 & 50-100 & \\
\hline
\end{tabular}

${ }^{*}$ In the direction of crack propagation.

$\eta$ is the maximum portion of brittle intergranular fracture for the state.

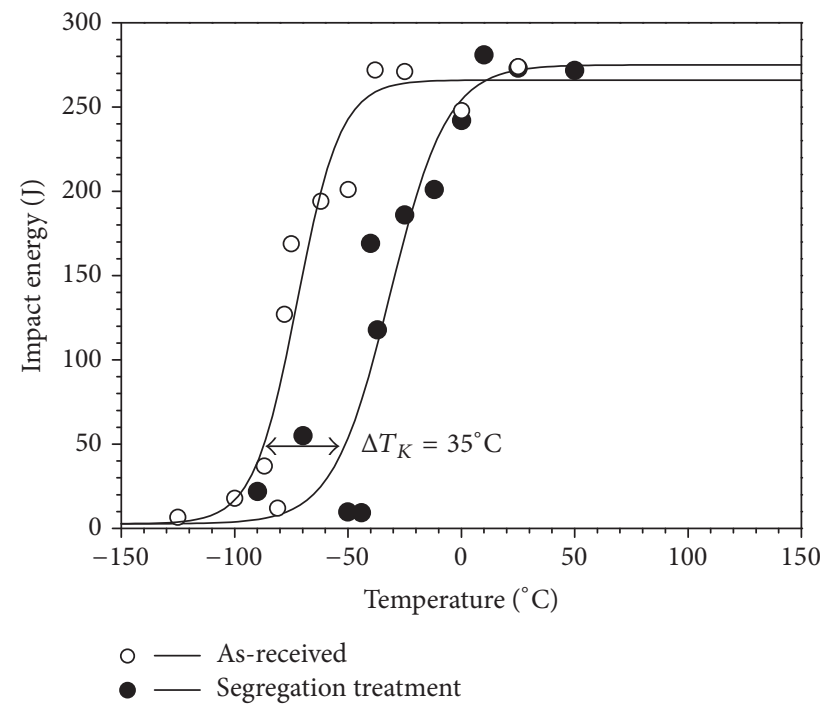

FIGURE 3: Ductile-to-brittle transition curves for 15Kh2NMFAA steel specimens: as-received and after segregation provoking treatment.

Measurement of grain boundary concentration of phosphorus and alloying elements in the 15Kh2NMFAA steel specimens after segregation provoking treatment was carried out by AES. Figure 5 shows frequency histograms of phosphorus grain boundary concentration in monolayer fractions in as-received specimens of the investigated steel and the specimens after segregation provoking treatment. Figure 6 demonstrates images of fracture surface with grain boundary regions for as-received and aged specimens obtained in PHI 700 Nanoprobe.
Segregation provoking treatment leads to a significant increase of phosphorus grain boundary concentration in the 15Kh2NMFAA steel specimens (up to $\sim 24 \%$ of the monolayer coverage on average as compared to $\sim 10 \%$ in the as-received specimens), resulting in the increase of the portion of brittle intergranular fracture in the fracture surfaces of the specimens after impact tests (up to $30 \%$ ). At that there is no contribution of the hardening mechanism of embrittlement. Therefore, the observed shift of critical brittleness temperature after segregation provoking treatment is exclusively due to the nonhardening mechanism-grain boundary segregations.

3.2. Influence of Irradiation at $300^{\circ} \mathrm{C}$ on Thermal and Radiation Stability of the Steel. The results of the study of initial hardening carbide phases as well as the average values of the parameters of the radiation-induced structural elements in the RPV steel irradiated at $300^{\circ} \mathrm{C}$ are presented in Table 5 .

Apparently irradiation at $300^{\circ} \mathrm{C}$ does not lead to changes in the number density and size of the initial hardening phases (the carbide phases) in the studied steel as compared to the as-received specimens.

Irradiation of $15 \mathrm{Kh} 2 \mathrm{NMFAA}$ steel at $300^{\circ} \mathrm{C}$ causes formation of radiation defects-dislocation loops and radiationinduced precipitates (based on $\mathrm{Ni}, \mathrm{Mn}$, and $\mathrm{Si}$ ) (see Table 4 for APT analysis of composition of the radiation-induced precipitates). Figure 7 shows TEM-images of radiationinduced structural elements, and Figure 8 demonstrates 3D mapping for the main elements included in the composition of precipitates.

Analysis of Table 5 shows that the contribution to the hardening of the steel irradiated at $300^{\circ} \mathrm{C}$ is made by radiation-induced precipitates and dislocation loops; at that the precipitates have a 2-orders-higher number density 

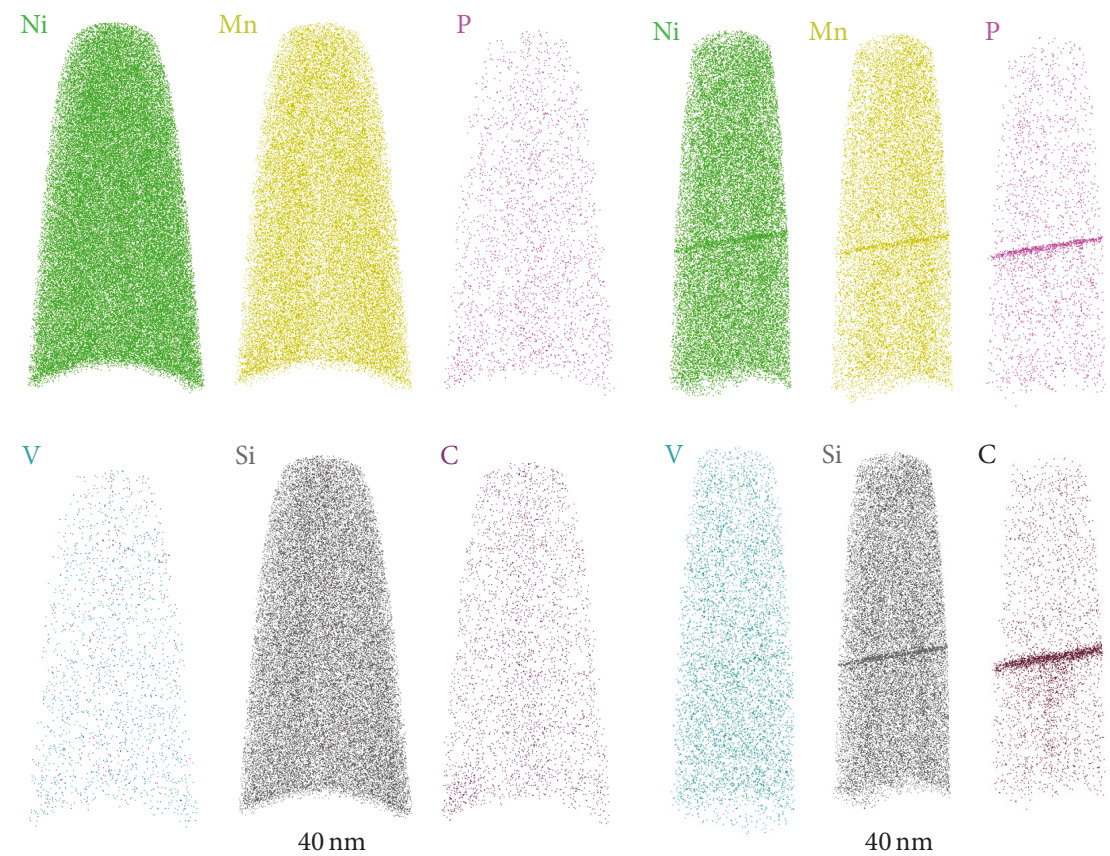

$\mathrm{C}$

(a)

(b)

FIGURE 4: 3D mapping of Ni, Mn, P, V, Si, and C in the steel obtained by APT: as-received specimen (a) and after segregation provoking treatment (b).

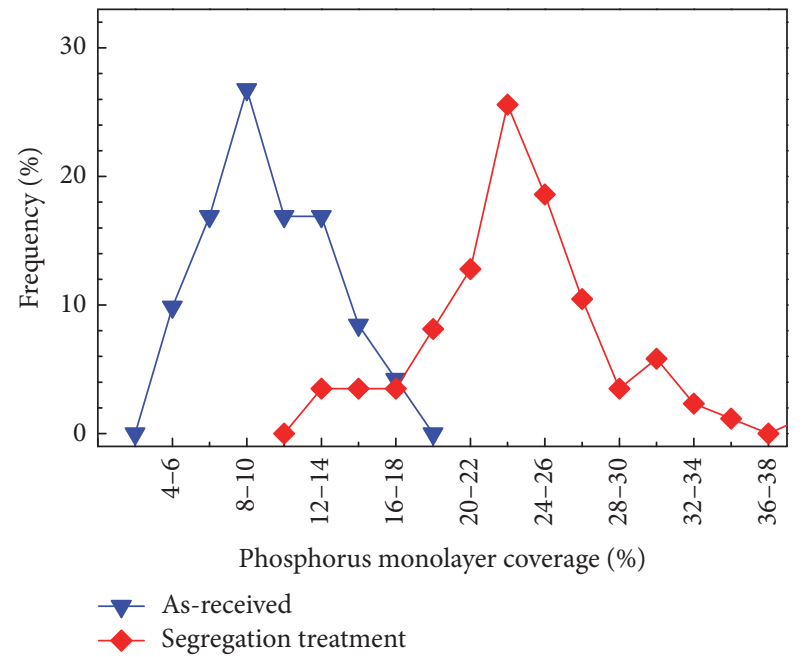

FIGURE 5: Grain boundary concentration of phosphorus in 15Kh2NMFAA steel specimens: as-received and after segregation provoking treatment.

compared to that of the radiation defects and make the main contribution to the hardening at the studied fast neutron fluence.

Results of AES study of grain boundary segregation of impurities showed that the change of phosphorus concentration in grain boundary after irradiation at $300^{\circ} \mathrm{C}$ is minimal as compared to the as-received specimens (see Figure 9) and is about $2 \%$ for the average value. However, it should be noted that the accelerated irradiation at the
TABLE 4: The result of APT analysis of average composition of precipitates.

\begin{tabular}{lcc}
\hline Elements & Matrix, at.\% & Precipitate, at.\% \\
\hline $\mathrm{Fe}$ & Bal. & Bal. \\
$\mathrm{Ni}$ & 1.68 & 17.2 \\
$\mathrm{Si}$ & 0.6 & 13.9 \\
$\mathrm{Mn}$ & 0.68 & 15.6 \\
$\mathrm{Cr}$ & 1.55 & 0.7 \\
$\mathrm{P}$ & 0.003 & 1.2 \\
$\mathrm{Cu}$ & 0.003 & 3.1 \\
\hline
\end{tabular}

given temperature leads only to radiation-enhanced diffusion of phosphorus with a minimum contribution of thermally stimulated diffusion due to small irradiation times. This small amount of phosphorus segregation does not lead to any portion of brittle intergranular fracture, which is $\sim 0 \%$ for the state based on the fractographic analysis results.

Thus, studies have shown that radiation embrittlement of $15 \mathrm{Kh} 2 \mathrm{NMFAA}$ steel caused by accelerated irradiation at operating temperature of VVER-1000-type RPV $\left(300^{\circ} \mathrm{C}\right)$ is mainly due to the hardening mechanism associated with the formation of radiation-induced precipitates and dislocation loops, as well as some contribution of the nonhardening mechanism associated with grain boundary segregation of impurities due to radiation-enhanced diffusion.

3.3. Influence of Irradiation at $400^{\circ} \mathrm{C}$ on Thermal and Radiation Stability of the Steel. The results of study of the hardening 


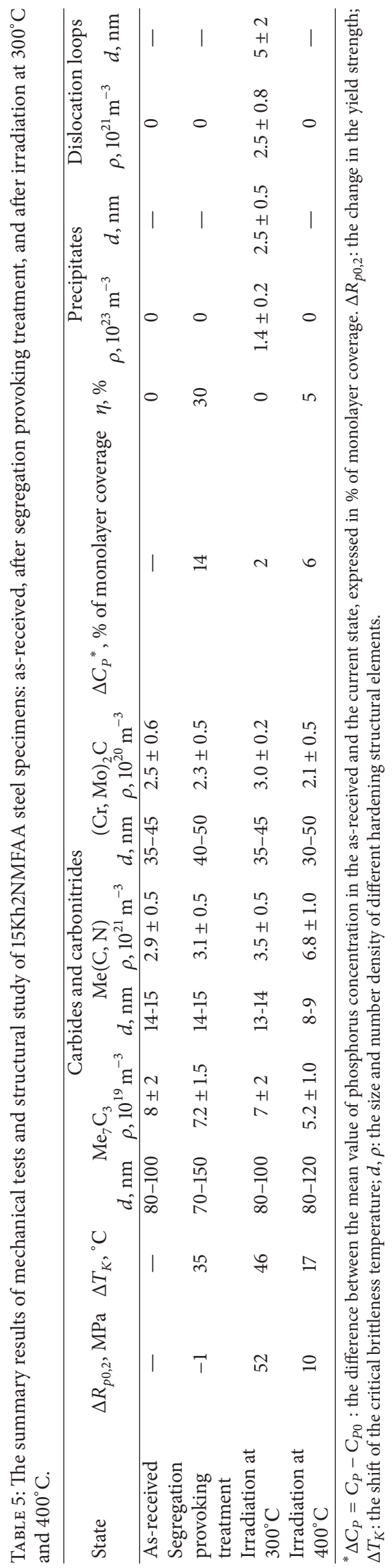




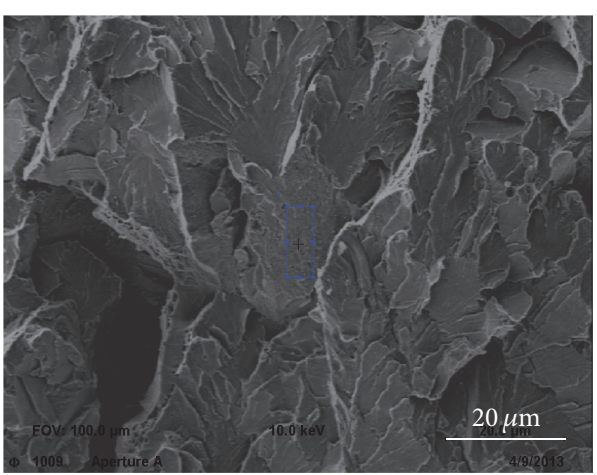

(a)

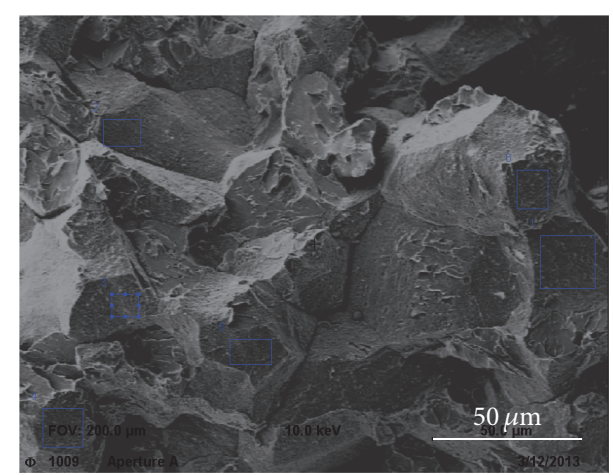

(b)

FIGURE 6: Images of grain boundary fracture surface for as-received (a) and aged (b) specimen obtained in PHI 700 Nanoprobe. Blue rectangles indicate areas of analysis for AES study.

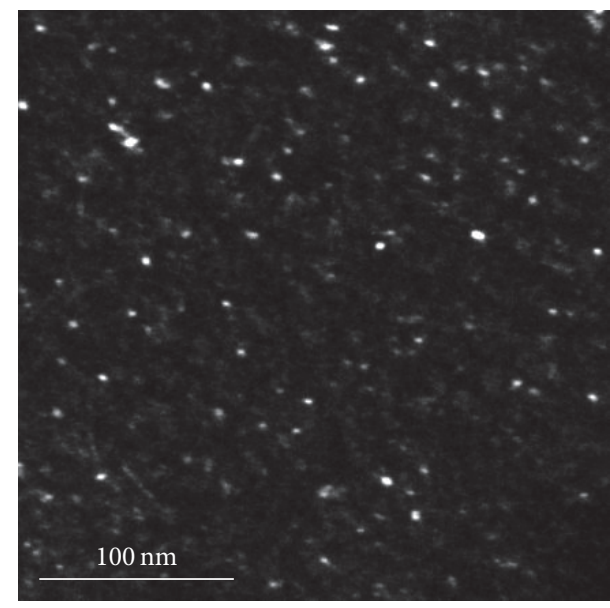

(a)

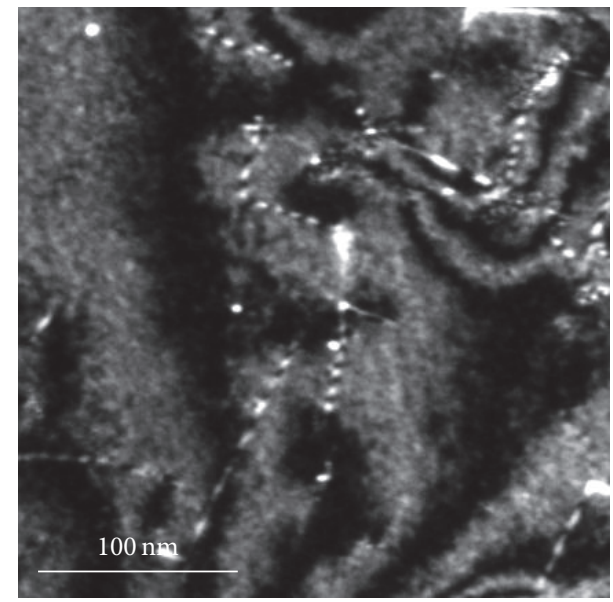

(b)

FIGURE 7: Radiation-induced structure elements in the 15Kh2NMFAA steel irradiated at $300^{\circ} \mathrm{C}$. Dark field TEM image: precipitates (a) and dislocation loops (b).
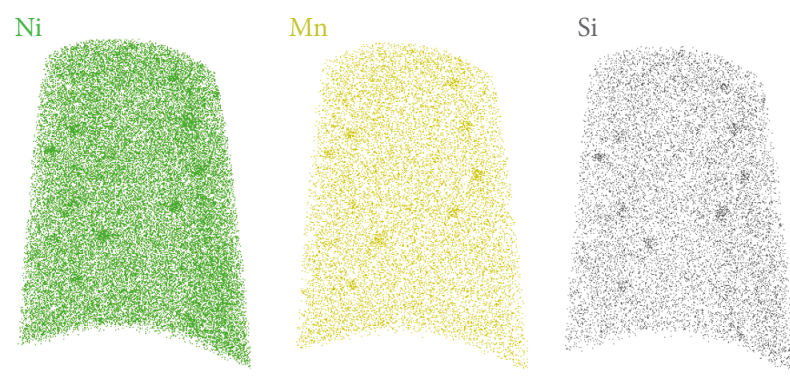

$30 \mathrm{~nm}$

FIGURE 8: 3D mapping of the elements forming radiation-induced precipitates in $15 \mathrm{Kh} 2 \mathrm{NMFAA}$ steel irradiated at $300^{\circ} \mathrm{C}$ obtained by APT.

phases in the as-received steel specimens and the ones after irradiation at $400^{\circ} \mathrm{C}$ are presented in Table 5 .

Figure 10 shows dark field TEM-images of carbonitrides in $15 \mathrm{Kh} 2 \mathrm{NMFAA}$ steel specimens: as-received and after irradiation at $400^{\circ} \mathrm{C}$.
The above TEM and SEM phase analysis of the steel showed (see Table 5), in contrast to irradiation at $300^{\circ} \mathrm{C}$, carbide transformations in the steel irradiated at $400^{\circ} \mathrm{C}$, resulting in $\sim 2.3$ times increase of number density of the main hardening phase-the carbonitrides-with decreasing of their size.

The TEM study of radiation-induced hardening phases has revealed no radiation defects-dislocation loops in $15 \mathrm{Kh} 2 \mathrm{NMFAA}$ steel irradiated at $400^{\circ} \mathrm{C}$, indicating either their absence for these irradiation conditions or that their number density and dimensions are below the detection limits of this method. This means that irradiation at elevated temperature (in this case at $T=400^{\circ} \mathrm{C}$ ) results in a noticeable annealing of radiation defect $[26,27]$, so that the dislocation loops are not formed. Furthermore, TEM and APT studies did not reveal any radiation-induced precipitates in the irradiated material either, indicating their absence for these irradiation conditions or that their number density and dimensions are below the detection limits of these methods.

Figure 11 shows a uniform 3D mapping of the main elements $(\mathrm{Ni}, \mathrm{Mn})$ forming radiation-induced precipitates, 


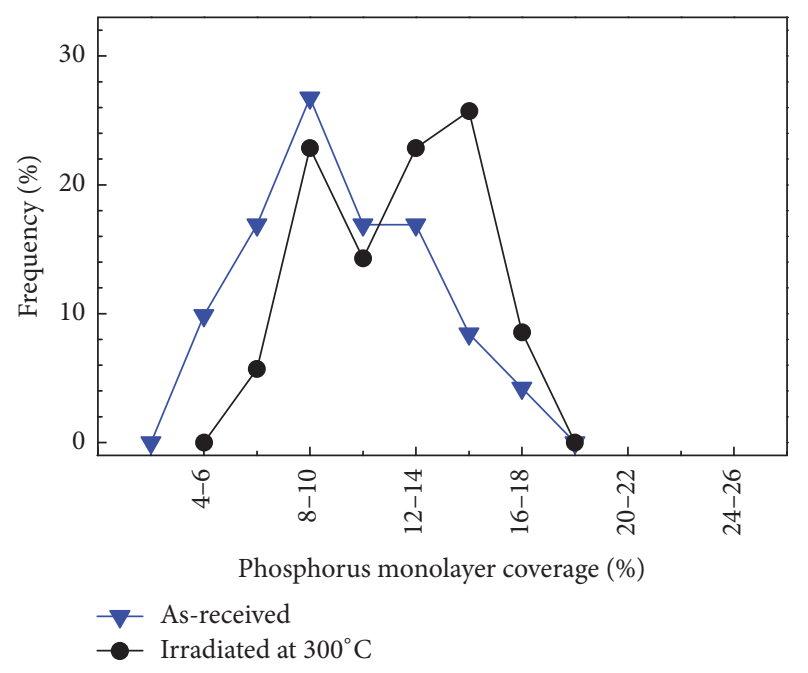

FIGURE 9: Grain boundary concentration of phosphorus in 15Kh2NMFAA steel specimens: as-received and after irradiation at $300^{\circ} \mathrm{C}$.

confirming the absence of these precipitates in the steel structure, as well as 3D mapping of $\mathrm{C}, \mathrm{V}$, and $\mathrm{Si}$ indicating $\mathrm{Me}(\mathrm{C}, \mathrm{N})$ carbonitrides in the studied region of the specimen. $3 \mathrm{D}$ mapping of $\mathrm{P}$ in Figure 11 demonstrates phosphorus enrichment of dislocations.

A possible reason for the lack of precipitates is the following. Both available formation centers being radiation defects and effective diffusion of the alloying atoms forming the precipitates are essential for precipitates formation [28]. However, despite the increased diffusional mobility as compared to the irradiation conditions at the operating temperature of VVER-1000-type RPV $\left(\sim 300^{\circ} \mathrm{C}\right)$, annealing of radiation defects does not allow radiation-induced precipitates to form at the given temperature $\left(400^{\circ} \mathrm{C}\right)$ and for the given fast neutron fluence $\left(4.4 \cdot 10^{23} \mathrm{~m}^{-2}\right)$.

Auger electron spectroscopy of grain boundary segregation of impurities was performed after irradiation at $400^{\circ} \mathrm{C}$. Figure 12 shows frequency histograms of phosphorus grain boundary concentration in monolayer fractions in the investigated steel irradiated at $400^{\circ} \mathrm{C}$ and in the as-received specimens.

Figure 12 shows that accelerated irradiation of $15 \mathrm{Kh} 2 \mathrm{NMFAA}$ steel at a temperature of $400^{\circ} \mathrm{C}$ increases grain boundary segregation of impurities in comparison with the as-received specimens ( $16 \%$ and $\sim 10 \%$ of phosphorus monolayer coverage, resp.).

It should be noted that accelerated irradiation at $400^{\circ} \mathrm{C}$ leads to a higher grain boundary phosphorus concentration in comparison with irradiation at $300^{\circ} \mathrm{C}$ in spite of the fact that irradiation at $400^{\circ} \mathrm{C}$ was performed in a research reactor and during a short time and with high flux. In this case, a higher level of grain boundary segregation is caused by enhanced thermal diffusion at a higher temperature along with the contribution of radiation-enhanced diffusion. Nevertheless, this level is significantly lower than the one obtained for the steel specimens after segregation treatment provoking formation of grain boundary segregation.
Fractographic analysis of Charpy specimens after impact tests of $15 \mathrm{Kh} 2 \mathrm{NMFAA}$ steel irradiated at $400^{\circ} \mathrm{C}$ showed that the portion of brittle intergranular fracture on the fracture surface, indicating formation of grain and interphase boundary segregation of impurities $[2,29,30]$, does not exceed $5 \%$.

Thus, the radiation embrittlement of steel irradiated at $400^{\circ} \mathrm{C}$ with high flux is also mainly due to the hardening mechanism associated with radiation hardening of the steel provided by carbide transformations resulting in some increase of number density of carbide phases. Besides, some contribution to embrittlement is made by the nonhardening mechanism associated with increasing of grain boundary segregation due to both radiation-enhanced diffusion and thermal enhancement of diffusion processes at a higher irradiation temperature.

3.4. Discussions. Table 5 shows the summary results of mechanical tests and structural study of $15 \mathrm{Kh} 2 \mathrm{NMFAA}$ steel in the as-received state, after segregation provoking treatment, and after irradiation at $300^{\circ} \mathrm{C}$ and $400^{\circ} \mathrm{C}$.

Analysis of Table 5 data reveals the features of the structure and mechanisms of radiation embrittlement of VVER1000-type RPV steel at different irradiation temperatures.

Radiation embrittlement at $300^{\circ} \mathrm{C}$ irradiation temperature as well as the one at irradiation temperature of $400^{\circ} \mathrm{C}$ is due to two mechanisms: radiation hardening and grain boundary segregation. However, radiation hardening in the case of irradiation at $300^{\circ} \mathrm{C}$ is due to formation of radiationinduced precipitates and radiation defects-dislocation loops of high number density. Radiation hardening in the case of irradiation at $400^{\circ} \mathrm{C}$ is associated with increased number density of the only hardening phase-the carbide one. At this the total number density of radiation-induced precipitates and dislocation loops after irradiation at $300^{\circ} \mathrm{C}$ is significantly higher than the change of the number density of the carbide phase after irradiation at $400^{\circ} \mathrm{C}$. This leads to the fact that the change of strength characteristics (yield strength change: $\left.\Delta R_{p 0,2}\right)$ in the case of irradiation at $300^{\circ} \mathrm{C}$ is greater than the one for irradiation at $400^{\circ} \mathrm{C}$. The contribution of change of grain boundary segregation after irradiation at $400^{\circ} \mathrm{C}$ is slightly higher than the corresponding contribution after irradiation at $300^{\circ} \mathrm{C}$. However, due to accelerated irradiation this contribution is lower than the one in the case of irradiation of surveillance specimens up to a close fluence [22, 31]. Since the hardening mechanism of radiation embrittlement is the main one for irradiation at $300^{\circ} \mathrm{C}$ and $400^{\circ} \mathrm{C}$, the shift of critical brittleness temperature $\left(\Delta T_{K}\right)$ after irradiation at $400^{\circ} \mathrm{C}$ is less than the corresponding shift after irradiation at $300^{\circ} \mathrm{C}$ (17 and $46^{\circ} \mathrm{C}$, correspondingly; see Table 5). Critical brittleness temperature shift of the steel after segregation treatment provoking the highest possible extent of grain boundary segregation is $35^{\circ} \mathrm{C}$, indicating the important role of grain boundary segregation in embrittlement of RPV steels.

The lowest shift of critical brittleness temperature after irradiation at $400^{\circ} \mathrm{C}$ demonstrates that this steel is a promising structural material for the new generation reactors that can be operated at an elevated temperature. 


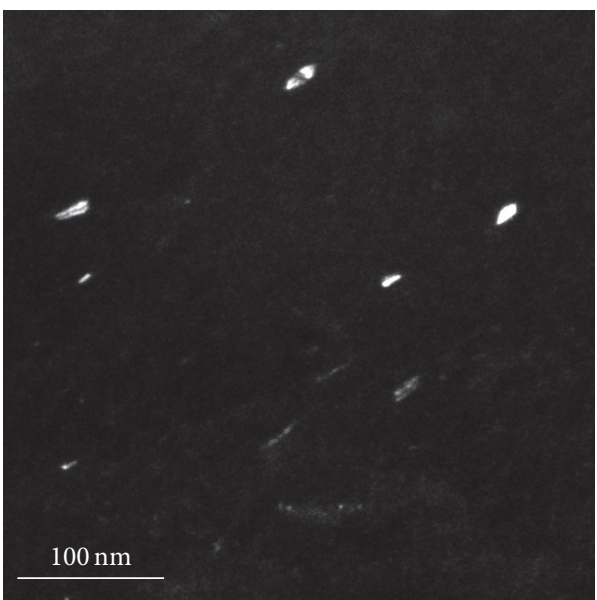

(a)

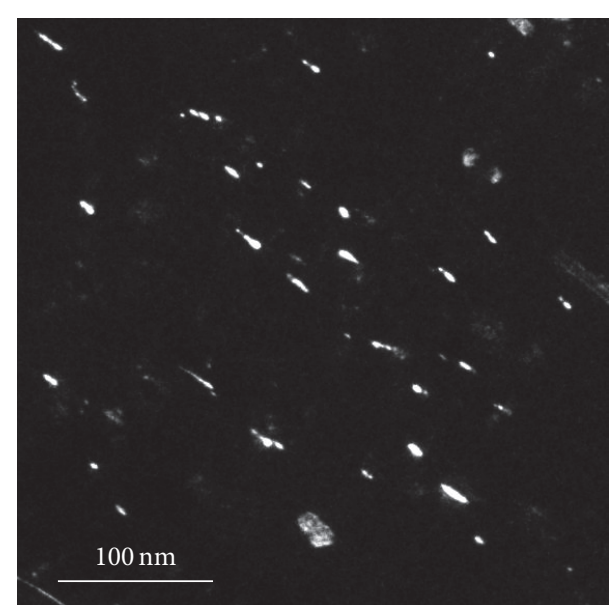

(b)

FIGURE 10: Dark field images of carbonitrides in 15Kh2NMFAA steel: (a) as-received specimen and (b) after irradiation at $400^{\circ} \mathrm{C}$.
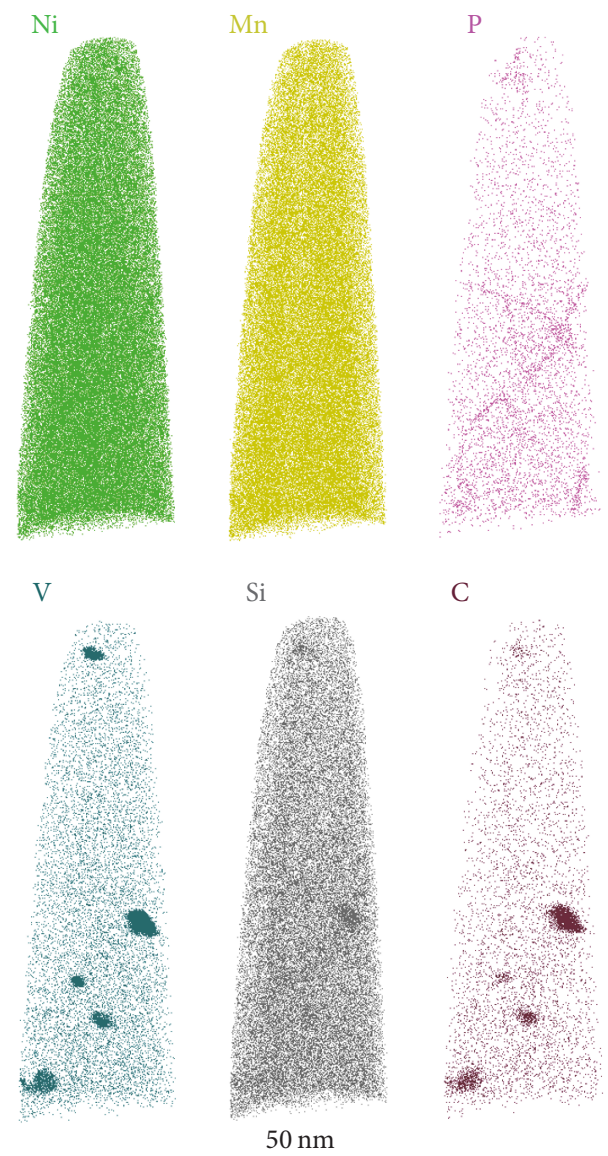

C

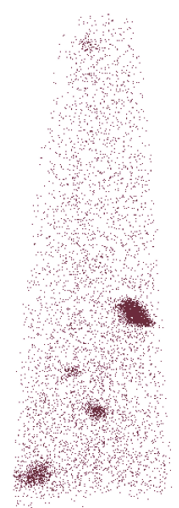

FIgURE 11: 3D mapping of $\mathrm{Ni}, \mathrm{Mn}, \mathrm{P}, \mathrm{V}, \mathrm{Si}$, and $\mathrm{C}$ obtained by APT in the steel irradiated at $T=400^{\circ} \mathrm{C}$.

\section{Conclusions}

(1) Mechanical tests and comprehensive structural studies are performed for $15 \mathrm{Kh} 2 \mathrm{NMFAA}$ steel in as-received state,

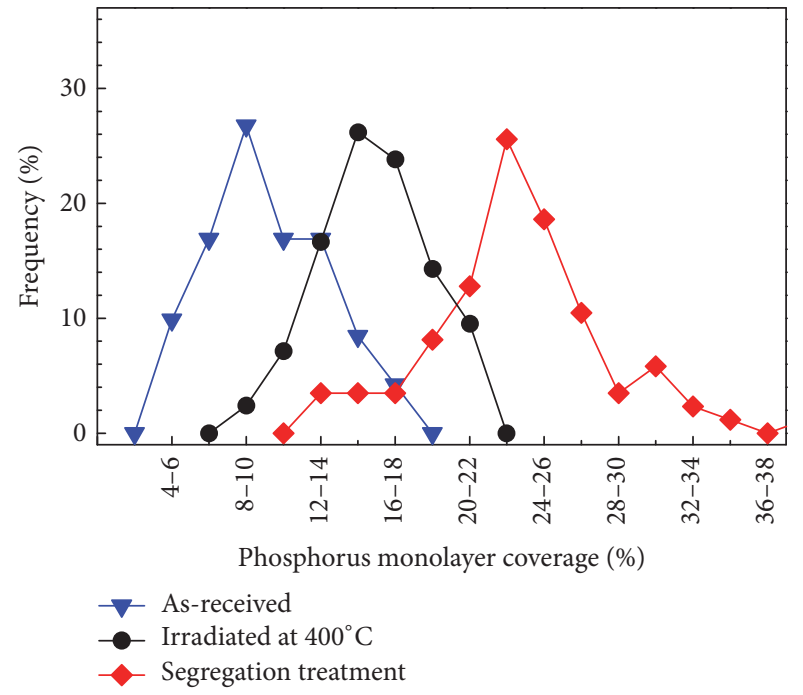

FIGURE 12: Grain boundary concentration of phosphorus in 15Kh2NMFAA steel specimens: as-received, after segregation provoking treatment, and after irradiation at $400^{\circ} \mathrm{C}$.

after segregation provoking treatment, and after accelerated irradiation at $300^{\circ} \mathrm{C}$ and $400^{\circ} \mathrm{C}$. At that the shifts of critical brittleness temperature, changes in yield strengths, and changes in number density and size of the initial carbide phases and radiation-induced structural components, along with the level of grain boundary segregation, are determined.

(2) The radiation embrittlement of $15 \mathrm{Kh} 2 \mathrm{NMFAA}$ steel during irradiation at $300^{\circ} \mathrm{C}$ is due to both the hardening mechanism associated with the formation of radiationinduced precipitates and dislocation loops and some contribution of the nonhardening one associated with grain boundary segregation of impurity and alloying elements due to radiation-enhanced diffusion during accelerated irradiation.

(3) Radiation embrittlement of 15Kh2NMFAA steel during irradiation at $400^{\circ} \mathrm{C}$ is mainly due to the hardening 
mechanism associated with an increase of the number density of the main hardening phase for this state, the $\mathrm{Me}(\mathrm{C}, \mathrm{N})$ carbonitrides, as well as some contribution of the nonhardening mechanism associated with some extent of grain boundary segregation due to both radiation-enhanced diffusion and thermal enhancement of diffusion processes at the elevated irradiation temperature.

(4) The studies have demonstrated the possibility of using 15Kh2NMFAA steel as a material for advanced reactor pressure vessels operated at elevated temperatures $\left(400^{\circ} \mathrm{C}\right)$.

\section{Conflicts of Interest}

The authors declare that there are no conflicts of interest regarding the publication of this paper.

\section{Acknowledgments}

The authors express their gratitude to D.Sci. D.Yu. Erak and Ph.D. D.A. Zhurko for performing irradiation experiment and the results of mechanical tests.

\section{References}

[1] B. Gurovich, E. Kuleshova, S. Fedotova, D. Maltsev, O. Zabusov, and A. Frolov, "Structural mechanisms of the flux effect for VVER-1000 reactor pressure vessel materials," in Contribution of Materials Investigations and Operating Experience to LWRs' Safety, Performance and Reliability, at Avignon, France-(Fontevraud, Sept. 14-18, 2014), pp. T01-T018, 2014.

[2] Y. Nishiyama, K. Onizawa, M. Suzuki et al., "Effects of neutronirradiation-induced intergranular phosphorus segregation and hardening on embrittlement in reactor pressure vessel steels," Acta Materialia, vol. 56, no. 16, pp. 4510-4521, 2008.

[3] Y. I. Shtrombakh, B. A. Gurovich, E. A. Kuleshova, D. A. Maltsev, S. V. Fedotova, and A. A. Chernobaeva, "Thermal ageing mechanisms of VVER-1000 reactor pressure vessel steels," Journal of Nuclear Materials, vol. 452, no. 1-3, pp. 348358, 2014.

[4] D. Erak, "Mechanical property changes of VVER RPV materials embrittlement (tensile-Charpy properties)," International Journal of Nuclear Knowledge Management, vol. 5, no. 1, pp. 53-79, 2011.

[5] G. R. Odette and G. E. Lucas, "Irradiation embrittlement of reactor pressure vessel steels: mechanisms, models, and data correlations," in Radiation Embrittlement of Nuclear Reactor Pressure Vessel Steels: An International Review, ASTM STP 909, L. E. Steele, Ed., vol. 2, pp. 206-241, American Society for Testing and Materials, Philadelphia, Pa, USA, 1986.

[6] M. Lambrecht, E. Meslin, L. Malerba et al., "On the correlation between irradiation-induced microstructural features and the hardening of reactor pressure vessel steels," Journal of Nuclear Materials, vol. 406, no. 1, pp. 84-89, 2010.

[7] J. Wu, S.-H. Song, L.-Q. Weng, T.-H. Xi, and Z.-X. Yuan, "An Auger electron spectroscopy study of phosphorus and molybdenum grain boundary segregation in a 2.25Cr1Mo steel," Materials Characterization, vol. 59, no. 3, pp. 261-265, 2008.

[8] Z. Lu, R. G. Faulkner, R. B. Jones, and P. E. J. Flewitt, "Radiationand thermally-induced phosphorus inter-granular segregation in pressure vessel steels," Journal of ASTM International, vol. 2, no. 8, pp. 351-365, 2005.
[9] B. A. Gurovich, E. A. Kuleshova, A. S. Frolov, and I. V. Teplukhina, "The thermal stability of the new steel for generation III + reactor pressure vessels," in The Materials of the Annual Conference of Young Scientists and Specialists "New Materials and technologie" Russia, Saint-Petersburg, CRISM "Prometey", 2013 (Russian).

[10] B. Gurovich, E. Kuleshova, O. Zabusov et al., "Influence of structural parameters on the tendency of VVER-1000 reactor pressure vessel steel to temper embrittlement," Journal of Nuclear Materials, vol. 435, no. 1-3, pp. 25-31, 2013.

[11] B. Gurovich, E. Kuleshova, Y. Shtrombakh et al., "Evolution of structure and properties of VVER-1000 RPV steels under accelerated irradiation up to beyond design fluences," Journal of Nuclear Materials, vol. 456, pp. 23-32, 2015.

[12] D. Y. Erak, D. A. Zhurko, and V. B. Papina, "Interpretation of accelerated irradiation results for materials of WWER-1000 reactor pressure vessels," Strength of Materials, vol. 45, no. 4, pp. 424-432, 2013.

[13] B. A. Gurovich, E. A. Kuleshova, D. A. Maltsev et al., "The effect of radiation-induced structural changes under accelerated irradiation on the behavior of water-cooled reactor pressure vessel steels," Key Engineering Materials, vol. 592-593, pp. 573576, 2014.

[14] REA, "Method of critical brittleness temperature determination using small-sized specimens impact bending test," RD EO 05982004, REA, St-Petersburg, Russia, 2004 (Russian).

[15] Standarts, "Metals. Methods of tension test," GOST 1497-84, Standarts, Moscow, Russia, 1997 (Russian).

[16] B. Gurovich, E. Kuleshova, Y. Shtrombakh et al., "Evolution of weld metals nanostructure and properties under irradiation and recovery annealing of VVER-type reactors," Journal of Nuclear Materials, vol. 434, no. 1-3, pp. 72-84, 2013.

[17] D. Williams and A. Carter, Electron Microscopy, Springer, New York, NY, USA, 2009.

[18] P. R. Mouton, Unbiased Stereology: A Concise Guide, Johns Hopkins University Press, Baltimore, Md, USA, 2011.

[19] B. A. Gurovich, Ya. I. Shtrombakh, Kuleshova, and S. V. Fedotova, "Structural criteria for selection of recovery annealing mode for VVER-1000 E.A. reactor pressure vessel materials," in VANT, Materials of Thermal Neutron Reactors, vol. 96, pp. 50$57,2010$.

[20] K. D. Childs, B. A. Carlson, L. A. Vanier et al., Handbook of Auger Electron Spectroscopy, Physical Electronics Inc, Eden Prairie, Minn, USA, 3rd edition, 1995.

[21] D. Briggs and M. P. Seah, Eds., Practical Surface Analysis by Auger and X-Ray Photoelectron Spectroscopy, John Wiley \& Sons, Chichester, UK, 1983.

[22] E. A. Kuleshova, B. A. Gurovich, Z. V. Lavrukhina, M. A. Saltykov, S. V. Fedotova, and A. N. Khodan, "Assessment of segregation kinetics in water-moderated reactors pressure vessel steels under long-term operation," Journal of Nuclear Materials, vol. 477, pp. 110-122, 2016.

[23] C. L. Briant, "Grain boundary structure, chemistry, and failure," Materials Science and Technology, vol. 17, no. 11, pp. 1317-1323, 2001.

[24] G. O. Williams, V. Randle, J. R. Cowan, and P. Spellward, "The role of misorientation and phosphorous content on grain growth and intergranular fracture in iron-carbon-phosphorus alloys," Journal of Microscopy, vol. 213, no. 3, pp. 321-327, 2004.

[25] P. Lejcek, Grain Boundary Segregation in Metals, Springer, Berlin, Germany, 2010. 
[26] S. J. Zinkle, P. J. Maziasz, and R. E. Stoller, "Dose dependence of the microstructural evolution in neutron-irradiated austenitic stainless steel," Journal of Nuclear Materials, vol. 206, no. 2-3, pp. 266-286, 1993.

[27] M. W. Thompson, Defects and Radiation Damage in Metals, Cambridge University Press, 1969.

[28] P. A. Platonov and A. A. Chernobaeva, "On the mechanism of precipitates formation in the reactor pressure vessel steels under neutron irradiation," VANT, Physics of Nuclear Reactors, vol. 5, pp. 78-93, 2015.

[29] B. A. Gurovich, E. A. Kuleshova, D. A. Maltsev, S. V. Fedotova, and A. S. Frolov, "Relationship of operational characteristics of steels for pressure vessels of nuclear reactors with evolution of its nanostructure in conditions of operation temperatures and irradiation," Problems of Atomic Science and Technology, no. 2, pp. 3-10, 2013.

[30] H. Nakata, K. Fujii, K. Fukuya, R. Kasada, and A. Kimura, "Grain boundary phosphorus segregation in thermally aged low alloy steels," Journal of Nuclear Science and Technology, vol. 43, no. 7, pp. 785-793, 2006.

[31] E. Kuleshova, B. Gurovich, Z. Lavrukhina et al., "Study of the flux effect nature for VVER-1000 RPV welds with high nickel content," Journal of Nuclear Materials, vol. 483, pp. 1-12, 2017. 


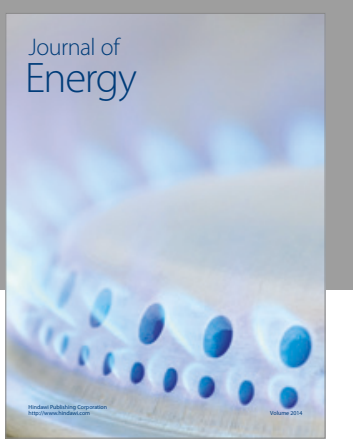

Journal of

Industrial Engineering
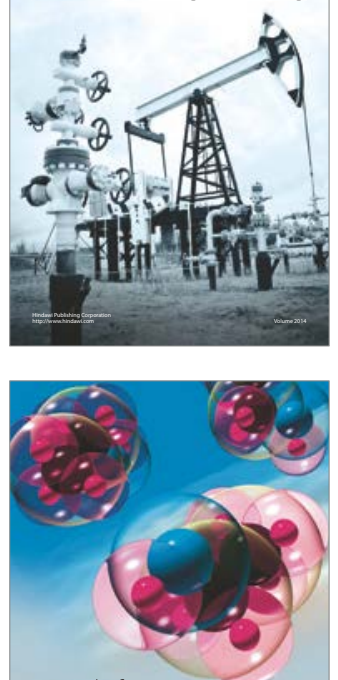

Fuels
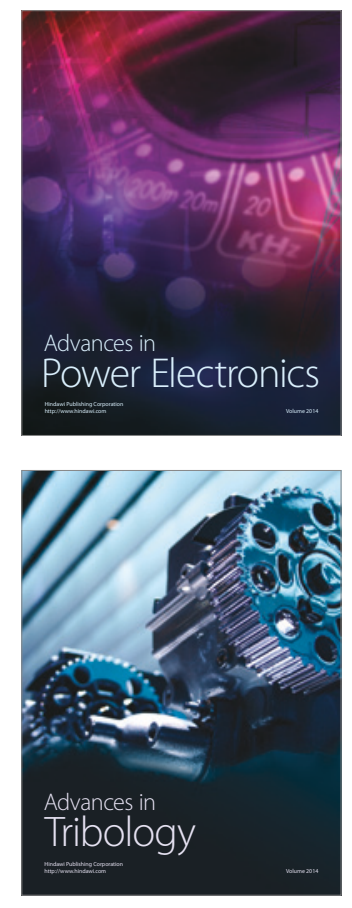
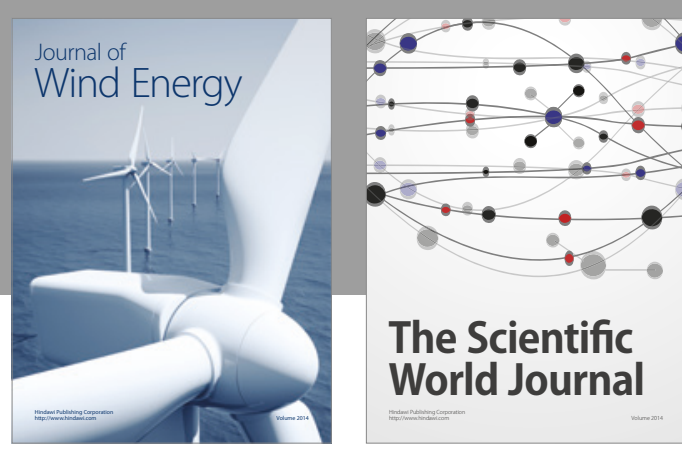

The Scientific World Journal
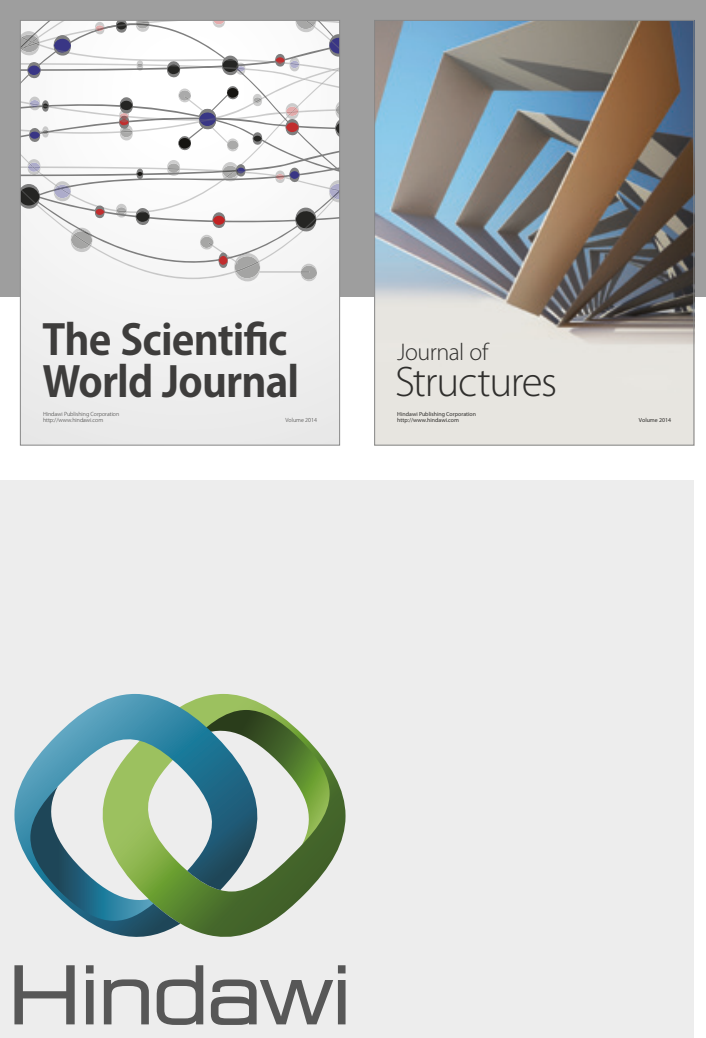

Submit your manuscripts at

https://www.hindawi.com
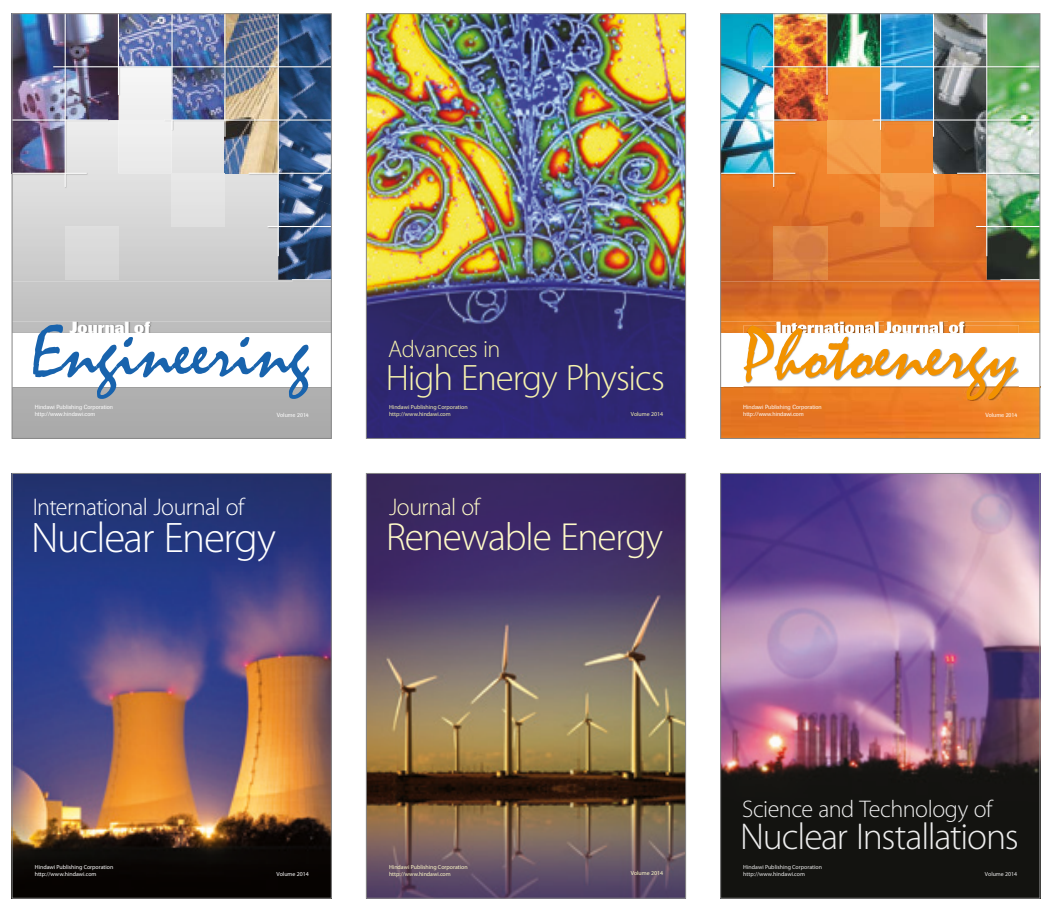

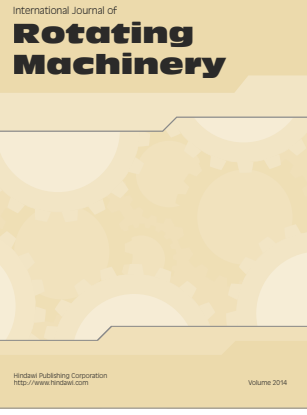

Journal of

Petroleum Engineering

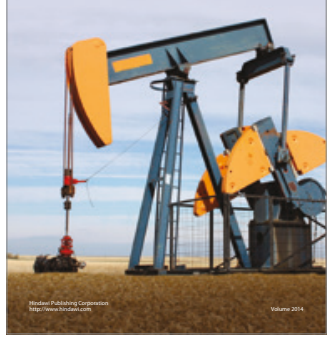

Journal of
Solar Energy
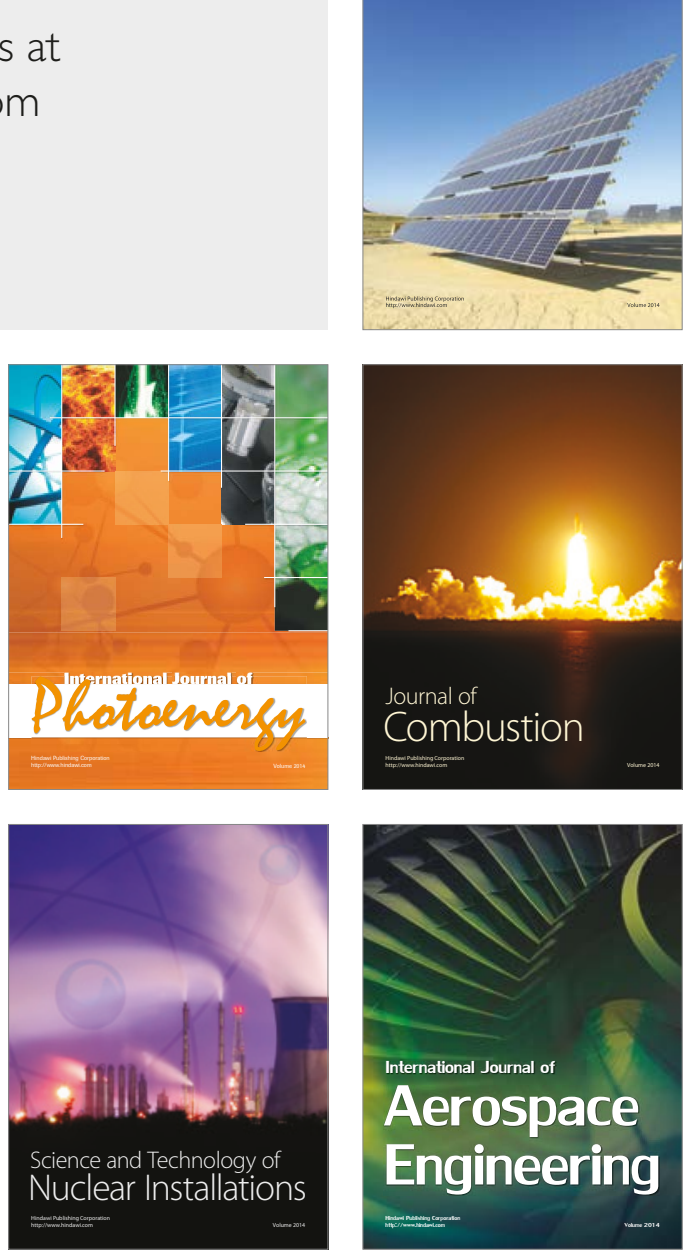